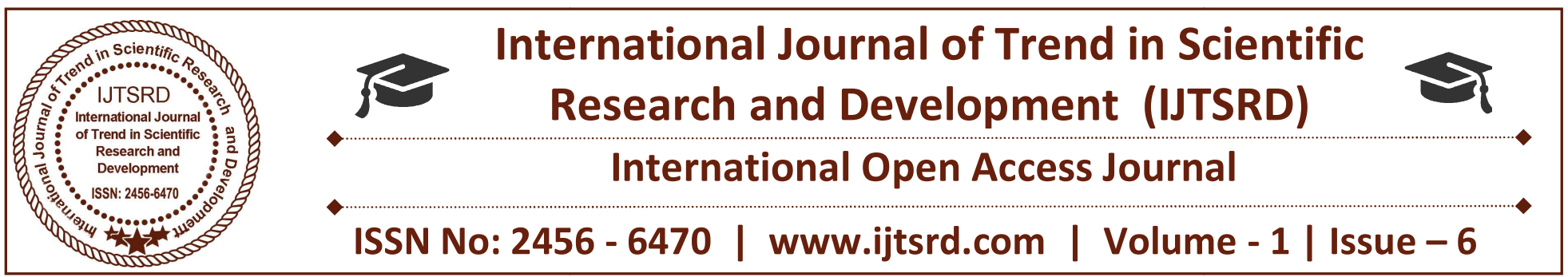

\title{
Initiative and Impact of Digital Library Consortium: An Overview
}

\author{
Dr. M. Manjula \\ Assistant Professor, DLIS, Srimad Andavan Arts \& \\ Science College, Trichy
}

\author{
R. Bhuvana \\ M.Lib.I.Sc Student, DLIS, Srimad Andavan Arts \& \\ Science College, Trichy
}

\section{ABSTRACT}

In the vast information technology era rapidly developing nation India needs a greater intellectual input to strengthen the education and research activities which needs strategic access of information and knowledge consortia is an economic model of resource sharing to meet the information needs with limited resources in the electronic environment. Shared subscription or consortia-based subscription to electronic resources through the consortia of libraries, on one hand, it permits successful deployment and easy access to electronic resources at a highly negotiated rates of subscription and on the other hand, it meets with the increasing pressures of diminishing budget, increased user's demand and rising cost of journals. Having understood the impact of consortia government of India supported many academic and research institutions to establish consortia in various areas of research and education institutions. In this paper we have made an attempt to discuss various consortia initiations and their impact in India.

Keywords: Digital Library Consortium, E-Journals, E-books, Information Technology, Impact

\section{Introduction}

Today as we are living in the knowledge society each and every sphere of human life in general and research and education in special depends on availability of the knowledge. There are many Medias to communicate the information produced by intellectual effort to further strengthen intellectual activities. Journals are the foremost sources as they are the carriers of new knowledge produced in various areas of research and education. Increasing demand for current information, scarcity of financial resources to subscribe all the journals forced to go for Cooperation and sharing. With the introduction of digital resources particularly E-Journals, origin of WWW and increasing price of e-journals made us to think of an economic model which can provide easy and feasible access with very negotiable and discounted cost where consortia came as a unique choice to meet all these requirements. From 1980s to till date India having very fruitful experience with consortia with greater contribution to various areas of research and education in a very economic way. There are many consortia initiations in India like INDEST, CSIR, UGC INFONET, IIM, FORSA, and HELINET. Next section we have made an attempt discuss the concept of consortia, models, advantages and disadvantages and Indian experience in consortia

\section{Concept of Library Consortia}

A consortium is an association of two or more individuals, companies, organizations or governments (or any combination of these entities) with the objective of participating in a common activity or pooling their resources for achieving a common goal. Consortium is a Latin word, meaning 'partnership, association or society'.

A Consortium could be described as a group of organizations who come together to fulfill a combined objective that usefully requires co-operation and the sharing of resources. And need to have a clear mutual goal in order to ensure their success. The aim should be to deliver "more than the sum of the individual 
parts". A library Consortium formation can be local, regional, state, national and inter institutional level. A library consortium brings together Librarians and libraries for activities and objectives that cannot be as effectively undertaken individually.

\section{Need for library consortium.}

The consortium is needed for libraries because of following reasons:

1. Information explosion

2. Diversity of user needs

3. Financial crunch

4. Impossibility of self-sufficiency

\section{Advantages of Consortia}

- Consortia-based subscription to electronic resources provides access to

- Wider number of electronic resources at substantially lower cost.

- Helpful to provide better library services like CAS and SDI

- Cost Sharing for Technical and training support

- Electronic Journals demand neither library space nor shelling costs nor canthey be stolen from the library

- Available 24 hours a day, 7 days a week

- Economy in maintain

\section{Disadvantages of Consortia}

- Absence of a printed copy of Journals

- Require training of staffs in handling electronic documents etc.

- Consortia require high initial investments in licensees and information and communication technology.

- Copyright problems

- Lack of archiving and back files availability

- Users are not accepting e-journals as per with the printed Journals

\section{Scope of Library Consortia}

\section{A) Information Resource Sharing}

A consortium can undertake the following activities for promoting information

resource sharing:

$>$ Cooperative collection development among the member libraries.

Cooperative processing of information resources acquired through the consortium.
Creation of virtual digital library covering all the e-information resources available in member libraries by networking of those libraries.

Sharing of information resources, both traditional and digital, of member libraries through network or document delivery service as the case may be.

$>$ Digitization of valuable and rare collections of member libraries available in printed format and providing access to such materials to the members of all the libraries of the consortium.

\section{B) Other Resource Sharing}

A consortium may also share other resources in the following manner for their mutual benefit of the participating libraries:

$>$ Sharing the storage facilities, thereby minimizing expenditure on space

$>$ Sharing of human resources at local, regional and national levels

$>$ Pooling of expert manpower and promoting professional development

Assist member libraries in creating information technology infrastructure

$>$ Facilitating joint preservation and archiving activities for print and digital materials

$>$ Initiating and supporting research projects of common interest

$>$ Collectively promoting, marketing and publicizing the library services

\section{Consortia Models}

The types of consortia identified are generally based on various models evolved in India in Varity of forms depending upon participations' affiliation and funding sources.

\section{Open Consortia}

This type of consortia is very flexible and it is the wish of members of consortia can join and leave anytime. INDEST Consortium is an example to the open consortia.

\section{Closed Group Consortia}

It is within defined group. This kind of consortia emerges either by affiliation and collaboration among them like CSIR, DAE, IIM Consortium. And the formation and operation of the consortia guidelines and its administration are fairly simple and easy. 


\section{Centrally Funded Model}

In this model, consortium will solely depend on the parent body. A few examples are INFONET by UGC, ICMR, and CSIR by DSIR.

\section{Shared-budget Model}

In this model the participating libraries take the lead and form the consortium. IIM and FORSA are examples of this model.

\section{Publisher Initiatives}

The Emerald Full-Text Library published by the Emerald Publishing Group (formerly MCB University Press) is recent example. Here, the consortium members will get deep discount price to the participating libraries

\section{National Consortium}

The end of this model is national level licensing of products. Examples are INDEST-AICTE, UGC Infonet.

\section{Major Library Consortia Initiatives in India}

India experienced very fruitful experience with library consortia. With the assistance of government and the MHRD many research institutions and higher education centres took sportive steps to establish library consortia and became every successful in their efforts. Following are the some important library consortiums established and providing very strategic platform for the negotiation and easy access of ejournals.

INDEST- Indian National Digital Library in Engineering Sciences and Technology

The Ministry of Human Resource Development (MHRD) has set-up the "Indian National Digital Library in Engineering Science and Technology (INDEST) Consortium" on their commendation made by the Expert Group appointed by the ministry under the chairmanship of Prof. N. Balakrishnan. The Ministry provides funds required for subscription to electronic resources for(48) institutions including IISc, IITs, NITs, IIMs and a few other centrallyfunded Government institutions through the consortium headquarters set-up at the IIT Delhi.

\section{FORSA-Forum for Resource Sharing in Astronomy} and Astrophysics

In the early 1980 s, due to proliferation of information, library professionals working in the Institutes where astronomy was one of the main thrust areas of research felt the need to come together and to form a forum, which can act as a springboard for sharing and exchange of information. The sheer necessity brought all likeminded astronomy librarians in the country together and a first meeting was held on July 291981 at Raman Research Institute, Bangalore and informally launched FORUM FOR RESOURCE SHARING IN ASTRONOMYAND ASTROPHYSICS FORSA with a vision and mission to share resources held in each library. At present, there are eleven institute members, viz. ARIES, Bose Institute, CASA-OU,HCRI, IIA, IUCAA, NCRA (TIFR), PRL, RRI, SINP* and TIFR

\section{CSIR Consortia (National Knowledge Resource Consortium (NKRC)}

The National Knowledge Resource Consortium (NKRC), established in year 2009, is a network of libraries and information centres of 40 CSIR and 26 DST institutes. NKRC's origin goes back to the year 2001, when the CSIR set up the Electronic Journals Consortium to provide access to 1200 odd journals of Elsevier Science to all its users. Over a period of time, the Consortium not only grew in terms of the number of resources but also in terms of the number of users as more like-minded institutes evinced interest to join the Consortium.

\section{IIM Library Consortia}

Need of resource sharing was realized by IIM Libraries a long back. Besides entering into the interlibrary loan practice, IIM Libraries also thought seriously of resource sharing in many other areas such as cooperative acquisition, cooperative processing and decentralized utilization. The concept of IIM Consortium has been floated a few years back. IIM Consortium is becoming a reality. The two areas were identified for partnership viz., a. developing the collection on shared basis and b) developing the services for exploiting such collection.

\section{UGC INFONET Digital Library Consortium}

The UGC-Infonet Digital Library Consortium was formally launched in December, 2003 by Honorable Dr. A P J Abdul Kalam the President of India soon after providing the Internet connectivity to the universities in the year 2003 under the UGC-Infonet programme. The Consortium proved to be a recipe to university libraries which have been discontinuing subscription of scholarly journals because of" Serials Crisis". The term "serials crisis" refers to exponential 
and continuing increase in subscription cost of scholarly journals.

\section{ICMR Consortia}

ICMR has been subscribing to the following ejournals in a consortia mode to all ICMR institutes. All the scientists can access these journals from their desktop. NLM, Science, NEJM, Lancet, Nature.

\section{Conclusion}

No library today is independently competent to serve dynamic needs of their users with limited resources. A Library cannot succeed alone without cooperation, Satisfaction of information needs of the today's research and education is more than ever a question of cooperation. In this situation the consortium, with its collective strength of participating institutions, has attracted highly discounted rates of subscription with most favorable terms of agreement. Consortia are tools, which will aid in exploiting the features of the e-journals as well as in effecting savings which leads to optimum satisfaction with limited resources.

\section{REFERENCES:}

1) Jagdish Arora. The International Information \& Library Review, Volume 35, Issue

2) Goudar, IRN. and Poornima Narayana. 'Emerging pricing models for EJournalsConsortia and Indian initiatives'. Proceedings of the International Conference on Digital Libraries (ICDL 2004). New Delhi. 24-27 February 2004. 333-341.

3) Janakiraman, S., 'Thoughts on Library Consortium', Proceedings of the Round Table on Sharing of E-journals through Consortia in Indian Libraries, Bangalore. 28-29 November 2002.

4) Vagiswari, A. \& Louis, Christina, 1998, Networking of Astronomy Libraries and Resource Sharing in India, Proceedings of LISA III conference held in Puerto de la Cruz,Tenerife, Spain 21-24, 1998, ed. Grothkopf et al.;ASP Conf. Series, vol. 153, pp. 237-243.

5) http://paniit.iitd.ac.in/indest/

6) http://web.inflibnet.ac.in/info/ugcinfonet/ugcinfo net.jsp

7) http://www.iiap.res.in/library/forsa.html

8) http://www.niscair.res.in/ActivitiesandServices/ MajorProjects/majproj.htm\#ejournalconsortia 